\title{
Assessing residence times of hyporheic ground water in two alluvial flood plains of the Southern Alps using water temperature and
} \section{tracers}

\author{
E. Hoehn and O. A. Cirpka
}

Swiss Federal Institute of Aquatic Sciences and Technology (Eawag), Dübendorf, Switzerland

Received: 18 November 2005 - Published in Hydrol. Earth Syst. Sci. Discuss.: 27 March 2006

Revised: 7 July 2006 - Accepted: 17 July 2006 - Published: 27 July 2006

\begin{abstract}
Water temperature can be used as a tracer for the interaction between river water and groundwater, interpreting time shifts in temperature signals as retarded travel times. The water temperature fluctuates on different time scales, the most pronounced of which are the seasonal and diurnal ones. While seasonal fluctuations can be found in any type of shallow groundwater, high-frequency components are more typical for freshly infiltrated river water, or hyporheic groundwater, and are thus better suited for evaluating the travel time of the youngest groundwater component in alluvial aquifer systems. We present temperature time series collected at two sites in the alpine floodplain aquifers of the Brenno river in Southern Switzerland. At the first site, we determine apparent travel times of temperature for both the seasonal and high-frequency components of the temperature signals in several wells. The seasonal signal appears to travel more slowly, indicating a mixture of older and younger groundwater components, which is confirmed by sulphate measurements. The travel times of the high-frequency component qualitatively agree with the groundwater age derived from radon concentrations, which exclusively reflects young water components. Directly after minor floods, the amplitude of temperature fluctuations in an observation well nearby the river is the highest. Within a week, the riverbed is being clogged, leading to stronger attenuation of the temperature fluctuations in the observation well. At the second site, very fast infiltration to depths of $1.9 \mathrm{~m}$ under the riverbed could be inferred from the time shift of the diurnal temperature signal.
\end{abstract}

\section{Introduction}

Rivers of the Southern Alps are characterized by flashy erosive discharge patterns, e.g., during thunderstorms and snowmelt. In flood plains, floods lead to an enhanced exchange between the rivers and groundwater of alluvial sand and gravel aquifers (Brunke and Gonser, 1997; Huggenberger et al., 1998). The transition zone between rivers and groundwater is a heterogeneous ecotone characterized by down- and upwelling, and by various types of wetlands and small-scale habitats, which sustain high biodiversity within floodplain reaches (e.g. Stanford and Ward, 1993; Stanford et al., 1994; Brunke et al., 2003). We distinguish hyporheic groundwater (freshly infiltrated water, in the sense of Triska et al., 1990) from other alluvial groundwater by its short residence time in the subsurface of up to a few days and its low proportion $(<50$ per cent) of alluvial groundwater. Older alluvial groundwater originates from regional recharge (precipitation on the flood plain or downwelling of upstream river reaches), or from the hillslope drainage system.

River water is also withdrawn for the generation of hydroelectric power. The withdrawal of water leads to a lowerthan-normal downstream residual flow pattern and to a reduction of the number of floods and of the river's maximum discharge rates during floods (Brunke, 2002). Furthermore, the reduction in flood frequencies and the reduction of peak flows decrease the interaction between the river and its floodplains. The lack of sufficient water in a river is a stress factor for benthic invertebrates and fish.

In groundwater resources protection, residence times play an important role, as it is believed that pathogenic bacteria do not survive long time periods in an aquifer. Typical regulations for outlining protection zones are based on maximum residence times (10 days in Switzerland, 50 days in Germany). In many floodplains of central Europe, groundwater is used for drinking water that contains a significant

(hoehn@eawag.ch)

Published by Copernicus GmbH on behalf of the European Geosciences Union. 
contribution of bank filtrate. Wells are located close to the river, and are, therefore, vulnerable to contamination.

Abiotic aspects of the exchange of water at the river/aquifer interface have been described by the chemical water composition (e.g. von Gunten et al., 1991; Bourg and Bertin, 1994), the use of ${ }^{222} \mathrm{Rn}$ as an environmental tracer (e.g. Hoehn and von Gunten, 1989; Bertin and Bourg, 1994), and water temperature (e.g. Constantz et al., 2002; Anderson, 2005). The present study is embedded in a research project on the response of Alpine catchments to hydropower operations (Truffer et al., 2003). Here, we interpret temperature time series in the river and in monitoring wells. The temperature data should show whether some wells close to the river are influenced by downwelling river water that becomes very young "hyporheic" groundwater. We compare the temperature data with other tracers to assess the extent of the exchange between the river and the groundwater.

\section{Groundwater flow rates and temperatures of infiltrat- ing river water}

In a losing reach of a river, the water loss specific to a square meter of the wetted riverbed (specific infiltration rate of the riverbed), $q$, is related to the mean residence time of freshly infiltrated water, $\bar{\tau}_{w}$ ) as follows:

$q=\frac{x n_{e}}{\bar{\tau}_{w}}$,

where $x$ is the path length from the infiltration point in the river to a nearby monitoring well, and $n_{e}$ is the flow-effective porosity of the riverbed and aquifer materials. The average linear flow velocity of a water particle is the seepage velocity $\bar{v}_{w}$ :

$\bar{v}_{w}=q / n_{e}=x / \bar{\tau}_{w}$.

The specific infiltration rate varies with time, depending on the discharge rate of the river, and the sediment load, temperature, chemical and biological parameters of the river water. Hydraulic clogging of the riverbed (colmatation, silting) may occur in periods of low flow, especially at higher water temperatures, or as a result of a high load of fine-grained suspended solids (Schälchli, 1993; Sophocleus, 2002). The clogging of the pore space in the riverbed material is characterized by a deposition of inorganic or organic fine-grained sediments (wash load), at or near the riverbed surface. Consequences of the clogging of riverbeds are a "cementation" of the bed structure, a decrease of hydraulic conductivity $K$, and thus a decrease in the exchange rate between river and groundwater. During floods, these layers are eroded quickly, and both $K$ and $q$ increase (Schälchli, 1993). Hoehn (2002) compiled values of $q$ between 0.05 and $4 \mathrm{~m} /$ day from direct measurements in coarse-grained beds of losing Alpine rivers.
2.1 One-dimensional analysis of heat and solute transport of infiltrating river water

Heat transfer in granular material is mainly characterized by convection and conduction/dispersion. Assuming local thermal equilibrium between groundwater and the sediment matrix, the heat transfer within a non-interacting stream tube can be described by the one-dimensional convectionconduction equation (e.g., Domenico and Schwartz, 1990, Eq. 9.21):

$\frac{\partial T}{\partial t}+q \frac{\rho_{w} C_{w}}{\rho_{b} C_{b}} \frac{\partial T}{\partial x}-D_{T} \frac{\partial^{2} T}{\partial x^{2}}=0$,

in which $T$ denotes temperature, $D_{T}$ is the effective thermal diffusivity of the aquifer, merging the effects of heat conduction through both the aqueous and solid phase and hydrodynamic dispersion of temperature; $\rho$ and $C$ denote the gravimetric density and specific heat capacity of water $\left(\rho_{w}, C_{w}\right)$, aquifer sediment $\left(\rho_{s}, C_{s}\right)$, and of the bulk granular medium (sediment and water: $\rho_{b}, C_{b}$ ), respectively, in which the bulk properties are computed by:

$\rho_{b} C_{b}=n_{e} \rho_{w} C_{w}+\left(1-n_{e}\right) \rho_{s} C_{s}$.

For comparison, the transport of an ideal tracer in the same stream tube follows the advection-dispersion equation (e.g., Domenico and Schwartz, 1990, Eq. 13.11):

$\frac{\partial c}{\partial t}+\frac{q}{n_{e}} \frac{\partial c}{\partial x}-D \frac{\partial^{2} c}{\partial x^{2}}=0$,

in which $c$ denotes concentration, and $D$ is the hydrodynamic dispersion coefficient. Obviously, Eqs. (3) and (5) are formally identical, only the coefficients differ slightly. The first difference between solute and heat transport is in the diffusive term. On the pore scale, $D_{T}$ is significantly larger than the solute dispersion coefficient $D$. As we will see, this leads to strong dampening of high-frequency temperature fluctuations. The second difference lies in the advective term. The linear transport velocity $\bar{v}_{T}$ of strictly convective temperature transport is smaller in comparison to that of solute transport, $\bar{v}_{w}$ :

$\bar{v}_{T}=q \frac{\rho_{w} C_{w}}{\rho_{b} C_{b}}=\frac{\bar{v}_{w}}{R_{T}}$,

in which $R_{T}$ is the dimensionless retardation factor for temperature, which can be computed from the volumetric heat capacities of the bulk medium and of water alone:

$R_{T}=\frac{\bar{v}_{w}}{\bar{v}_{T}}=\frac{\rho_{b} C_{b}}{n_{e} \rho_{w} C_{w}}$.

Temperature retardation factors between 2.5 and 3.5 were reported for glaciofluvial outwash materials (e.g., Jäckli and Ryf, 1978; Bonnard et al., 1991). Average values of $\rho_{s} \approx 2^{\prime} 650 \mathrm{~kg} / \mathrm{m}^{3}$ and $C_{s} \approx 2.3 \times 10^{6}(\mathrm{~J} / \mathrm{kg} \times \mathrm{K})$ for alpine alluvial material (mainly quartz, felspars, and calcite) result 
in $\rho_{b} C_{b} / \rho_{w} C_{w}$ of 0.65 (compare with Table 10.4. of de Marsily, 1986). A value of 0.625 for $\rho_{b} C_{b} / \rho_{w} C_{w}$ was used by Sauty (1978) for an interpretation of injections of hot water into an aquifer. From this and $R_{T}=3$ results an effective aquifer porosity of $n_{e}$ of $0.21-0.22$. In the following analytical expressions, all heat-transfer properties are assumed uniform over the path length. These expressions are used to exemplify the effects of diffusion and advection on the propagation of temperature fluctuations with different frequencies. In the subsequent analysis of experimental data, only the temperature retardation factor is assumed constant, so that travel times of temperature can be mapped to those of solutes.

River water temperatures fluctuate on different time scales. Most dominant are seasonal and diurnal fluctuations. We now analyze how a sinusoidal temperature fluctuation, $T_{w}^{\prime}$, in the river is propagated into the aquifer. We consider a semiinfinite groundwater stream tube with constant and uniform flow coefficients. The sinusoidal temperature fluctuation is fixed at the inflow boundary $(x=0)$ whereas it vanishes in the large-distance limit $(x \rightarrow \infty)$ :

$$
\begin{aligned}
& T_{w}^{\prime}(x=0, t)=a_{0} \cos (2 \pi t f) \\
& \lim _{x \rightarrow \infty} T_{w}^{\prime}(x, t)=0
\end{aligned},
$$

in which $a_{0}$ is the amplitude of the temperature fluctuation in the river, and $f$ is the frequency (e.g., 1/year, or 1/day). The closed-form solution of this problem is (Logan, 1996, Sect. 4):

$T_{w}^{\prime}(x, t)=a_{0} a_{\mathrm{rel}}(x, f) \cos \left(2 \pi f\left(t-\frac{x}{v_{e}(f)}\right)\right)$

with the relative amplitude $a_{\mathrm{rel}}(x, f)$ and the celerity, or effective velocity $v_{e}(f)$ of wave propagation:

$$
\begin{aligned}
& a_{\mathrm{rel}}(x, f)=\exp \left(\frac{\bar{v}_{T}-v_{e}}{2 D_{T}} x\right) \\
& v_{e}=\bar{v}_{T} \sqrt{\frac{1}{2}\left(1+\sqrt{1+\frac{64 \pi^{2} f^{2} D_{T}^{2}}{\bar{v}_{T}^{4}}}\right)} .
\end{aligned}
$$

In the limiting case of $f D_{T} / \bar{v}_{T}^{2} \rightarrow 0$, the celerity $v_{e}$ is identical to the retarded temperature velocity $\bar{v}_{T}$, and $a_{\text {rel }}$ remains unity. Obviously, this condition is approached for low frequencies, high velocities and small thermal diffusion coefficients. Assuming $D_{T}=5 \times 10^{-7} \mathrm{~m}^{2} / \mathrm{s}$, diurnal temperature fluctuations are propagated to distances of more than $100 \mathrm{~m}$ in aquifers with very high velocity $\left(\bar{v}_{T} \approx 10 \mathrm{~m} /\right.$ day), while they are almost completely dampened when $\bar{v}_{T}$ is in the range of $1 \mathrm{~m} / \mathrm{d}$. Seasonal fluctuations, by contrast, are hardly dampened even with the lower velocity mentioned.

When we observe a temperature disturbance at two observation points, which are believed to belong to the same stream tube, we can evaluate a time shift $\bar{\tau}_{T}$ or apparent travel time of temperature, which relates to the mean residence time of water $\bar{\tau}_{w}$ by (e.g., de Marsily, 1986, p. 279):

$\bar{\tau}_{T}=\frac{\bar{v}_{T}}{v_{e}} R_{T} \bar{\tau}_{w}$.
That is, computing the residence time of water $\bar{\tau}_{w}$ from the travel time of temperature $\bar{\tau}_{T}$ is the easiest when the celerity $v_{e}$ is about $\bar{v}_{T}$. But, as indicated by Eq. (10), cases where $v_{e}$ is considerably larger than $\bar{v}_{T}$ result also in strong dampening of the temperature signal, so that the approximation $v_{e} \approx \bar{v}_{T}$ is valid in most cases where the propagation of temperature disturbances is observable.

\subsection{Mixing of groundwater stream tubes}

Monitoring wells are typically screened over a depth of at least $1 \mathrm{~m}$. This implies that the well samples several stream tubes, some of which may be carrying hyporheic groundwater, while others do not. Even if all the water sampled in the well originates from the river, the temperature signal, $T_{w}^{\prime}$, which is measured in the well and corresponds to a sinusoidal temperature fluctuation in the river, consists of the contributions of several different discharge fractions:

$T_{w}^{\prime}(t)=a_{0} \sum_{i} f_{i} a_{i}(x, f) \cos \left(2 \pi f\left(t-\frac{x}{v_{i}(f)}\right)\right)$,

in which $i$ is the index for a particular stream tube, $f_{i}$ is the fraction of discharge contributed by stream tube $i$, whereas $a_{i}$ and $v_{i}$ are the relative amplitude and celerity of that stream tube. The coefficients of the contributions of the various discharge fractions cannot be inferred from the coefficients of the mixture, even if the contributing fractions are known. In the limiting case of a binary mixture, in which only a single groundwater stream tube carries the signal of a temperature change, the signal amplitude of the mixture is multiplied by the flow fraction of that stream tube, while the phase angle is not changed. As discussed above, seasonal temperature fluctuations are hardly dampened. Therefore, practically every shallow groundwater carries a seasonal temperature signal. As a consequence, seasonal temperature fluctuations observed in monitoring wells in alluvial aquifers are difficult to interpret. Unless the well samples only hyporheic groundwater, the phase of the seasonal temperature fluctuation cannot be related to a particular residence time or flow velocity. Short-time events, by contrast, may be more specific: In most cases, a rapid temperature change in a flowing river (due to flash floods or diurnal changes) will not be accompanied by a similarly rapid temperature change in the "older" alluvial groundwater from regional recharge. Thus the transfer time of a temperature signal from the downwelling river to a monitoring well (delay) reflects the travel time of the "young" groundwater of river origin. The signal will be dampened by dispersion, thermal non-equilibrium and mixing with other groundwater stream tubes, but the observed time shift $\bar{\tau}_{T}$ is a unique indicator of the mean residence time $\bar{\tau}_{w}$ of hyporheic water.

Temperature variations in losing river systems should not be studied stand-alone. In the present study, we assess temperature variations at two sites. At the first site, mixing 


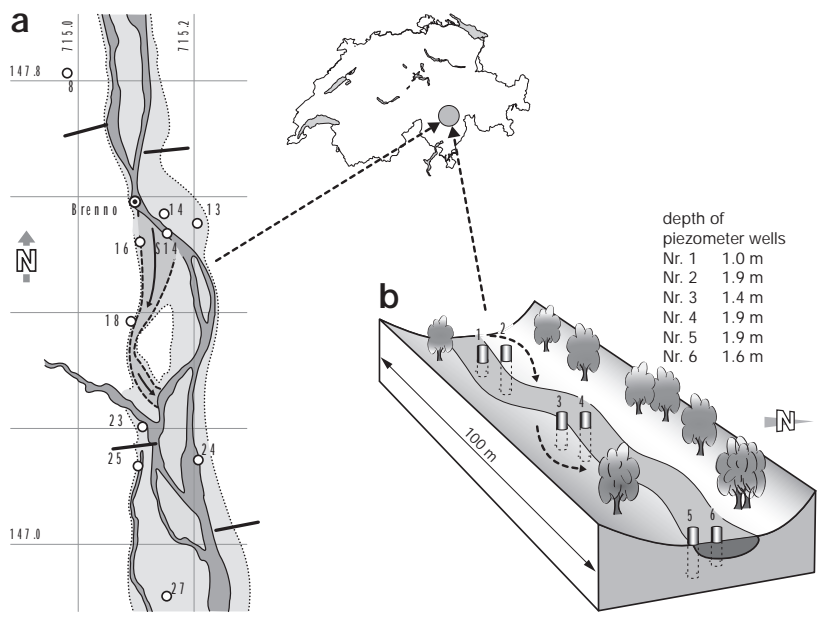

Fig. 1. Plan view of Valle di Blenio, Alps of Southern Switzerland. (a) Plan view of the first site: Circles: monitoring wells; dotted circles: logger in Brenno River; dashed line: flood bank; thin lines: bank structures; arrow: change of main river course by a flood. (b) Block diagram of the second site showing shallow monitoring wells; arrows: change of main river course by a flood.

ratios between young hyporheic and older alluvial groundwater with sulphate as a tracer for binary mixing. At this site, we furthermore assess the residence times of the young hyporheic groundwater using ${ }^{222} \mathrm{Rn}$ as a tracer for the water age (Hoehn and von Gunten, 1989). Rn-222 activity concentrations (here denoted as concentrations) are known to increase about exponentially with time in groundwater:

$c(t)=c_{\text {river }}+\left(c_{\infty}-c_{\text {river }}\right)(1-\exp (-\lambda t))$,

in which $c_{\text {river }}$ is the concentration in the river, $\lambda$ is the radioactive decay constant $\left(\lambda_{\mathrm{Rn}}=0.183 \mathrm{~d}^{-1}\right)$, and $c_{\infty}$ is the asymptotic ${ }^{222} \mathrm{Rn}$ concentration reached within the aquifer, when ingrowth and decay of dissolved ${ }^{222} \mathrm{Rn}$ is at steady state. Eq. (13) can be used to estimate groundwater residence times under the following assumptions: i) on the scale of the investigations, Rn progeny ( $\mathrm{U}, \mathrm{Th}, \mathrm{Ra})$ is uniformly distributed in the aquifer; ii) the assumption of steady-state $\mathrm{Rn}$ concentrations is valid for the investigated groundwater flow path; iii) Rn losses due to outgassing into the unsaturated zone and atmosphere can be neglected; and iv) sorption of $\mathrm{Rn}$ on surfaces of aquifer materials is negligible (Hoehn and von Gunten, 1989; Bertin and Bourg, 1994). The value of $c_{\infty}$ is specific for each aquifer as it depends on the amount of radium on the surface of the aquifer materials (Hoehn and von Gunten, 1989). The concentration reaches its asymptotic value within about four half lives of ${ }^{222} \mathrm{Rn}, t_{1 / 2(\mathrm{Rn})}$ of about $3.8 \mathrm{~d}\left(t_{1 / 2(\mathrm{Rn})}=\ln 2 / \lambda_{\mathrm{Rn}}\right)$. Increasing radon concentrations along a flow path thus indicate an increasing radon groundwater age $\left({ }^{222} \mathrm{Rn}\right.$ age, $\left.\tau_{\mathrm{Rn}}\right)$. Rearranging Eq. (13), and accounting for the fraction $f_{\text {inf }}$ of freshly infiltrated wa- ter, $\tau_{\mathrm{Rn}}$ is computed from concentration measurements by:

$\tau_{\mathrm{Rn}}=\frac{t_{1 / 2}}{\ln 2} \ln \left(\frac{c_{\mathrm{river}}-c_{\infty}}{\frac{c}{f_{\mathrm{inf}}}-c_{\infty}}\right)$,

in which $c$ is the concentration in the sample, $c_{\text {river }}$ is the concentration in the river reach (typically near zero), and the asymptotic concentration $c_{\infty}$ must be evaluated from groundwater samples in the aquifer of interest which are known to have a residence time of more than 15 days.

In this study, we assume that $\tau_{R n}$ is equivalent to the mean residence time of the very young hyporheic groundwater, $\bar{\tau}_{w}$. Radon concentrations yield residence times of up to 15 days (about 4 half lives), under plug-flow conditions. The results are compared with those of Holocher et al. (2001).

\section{Description of field sites and methods}

Two flood plains were investigated, which are both located in the catchment of the Brenno river, $\left(51 \mathrm{~km}^{2}\right.$, Valle di Blenio, Alps of southern Switzerland; see Fig. 1). The Brenno river is a tributary to the Ticino river and thus to the Po river. The two flood plains are separated by knick points (as defined by Brunke and Gonser, 1997) and have legally protected adjacent riparian wetlands. The natural flow regime of the Brenno river is nival, with high discharge rates in late spring due to snowmelt, floods in late summer due to thunderstorms, and otherwise low discharge rates. The natural flow regime of the river is altered by the withdrawal of water for hydropower generation, the water usually being withdrawn during the night (natural average discharge rate, $18 \mathrm{~m}^{3} / \mathrm{s}$; today's average discharge rate, $4.7 \mathrm{~m}^{3} / \mathrm{s}$; Brunke, 2002).

The first site was chosen in a riparian area located in the upper section of a flood plain of the Brenno River at an altitude of 540-580 m a.s.l. ("Middle Floodplain" of Holocher et al., 2001, and Brunke, 2002; see Fig. 1a), at which the authorities of Canton Ticino launched a reconnaissance study $\left(\right.$ CREA, 2005 ${ }^{1}$ ). The slope of the flood plain is about three per cent. The rocks in the Brenno river catchment consist mostly of paleozoic gneisses and schists, to a minor extent jurassic limestones and shales, and of triassic evaporite formations, with anhydrite, gypsum and dolomite as constituent minerals. From the latter, the Brenno river has high sulphate concentrations. The basis of the floodplain and the valley slopes consist mainly of silicate minerals from the crystalline basement of the Alps. Mazor and Vuataz (1990), Pastorelli et al. (1999), and Holocher et al. (2001) described deep bedrock groundwater, which is partly mineralized from Triassic evaporite rocks. The riverbed consists of coarse gravel, pebbles and cobbles. The floodplain is filled with poorly

\footnotetext{
${ }^{1}$ CREA (Consorzio Risanamento Ecosistemi Alluviali): Rapporto settioriale, Modello numerico di flusso dell'acquifero, unpublished final report, 2005.
} 

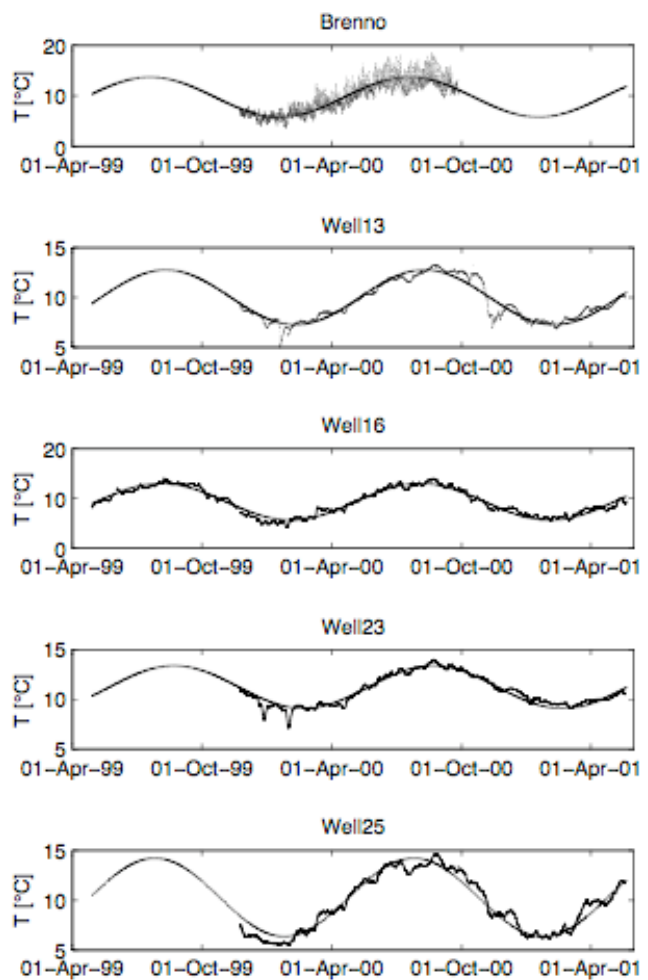
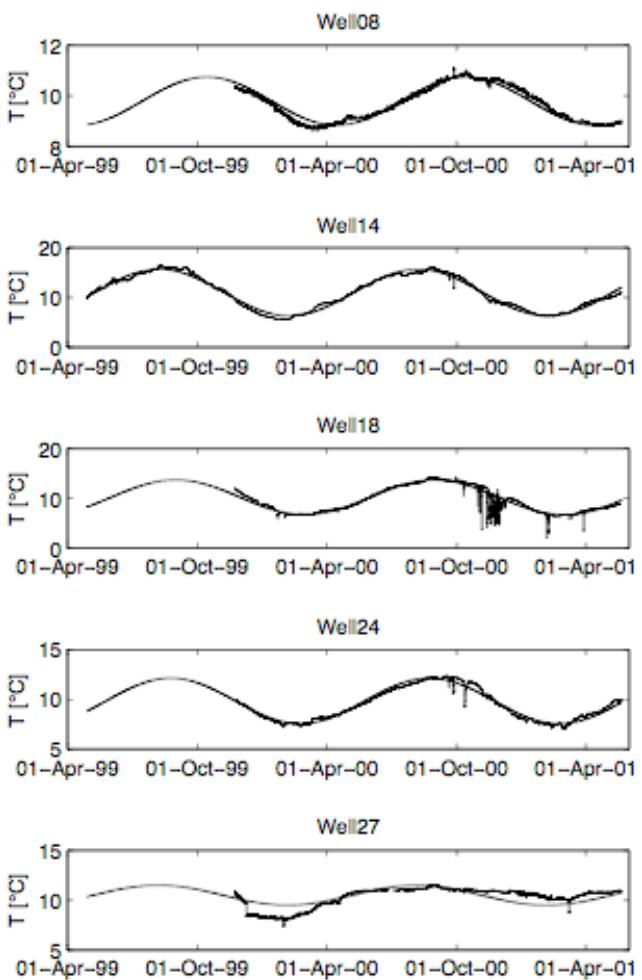

Fig. 2. Time series of measured water temperature in Brenno river and selected monitoring wells at the first site, May 1999-April 2001, with fit of sinusoidal seasonal trend.

sorted alluvial gravel and sand aquifer material to a thickness of slightly more than $10 \mathrm{~m}$. An aquifer transmissivity of $5 \pm 3 \times 10^{-3} \mathrm{~m}^{2} / \mathrm{s}$ was identified from 14 pumping tests in the boreholes $\left(\mathrm{CREA}, 2005^{1}\right)$. The water table fluctuates less inside an alluvial zone (parafluvial) where the riverbed is more active than outside (orthofluvial). The alluvial groundwater originates mainly from the valley slopes and from the river, in some places. The composition of the older alluvial groundwater is fairly constant with low sulphate concentrations. Only the hyporheic groundwater in the active riverbed has higher sulphate concentrations and is more mineralized, especially in winter (" $\mathrm{CaSO}_{4}$-dominated" in Holocher et al., 2001).

A total of 29 boreholes were drilled in the inner alluvial zone and instrumented with polyvinyl chloride (PVC) monitoring wells (diameter $0.05 \mathrm{~m}$; filter screens of $2 \mathrm{~m}$ length in saturated aquifer section). The water table is fluctuating by about $2 \mathrm{~m}$. The screened sections of the wells are located at depths of $1-5 \mathrm{~m}$ from the surface. They tap the top $2 \mathrm{~m}$ of ground water. The water table was low throughout most of the year, thus we neglected a possible smearing of the temperature signal. The wells were instrumented with piezoresistive probes (compensated for barometric pressure) for the measurement of hydraulic head and of water temperature (DL/N, STS AG, CH-8370 Sirnach, Switzerland; error of single measurement: $\pm 1 \mathrm{~cm}$ for head and $\pm 0.5 \mathrm{~K}$ for temperature, according to manufacturer's manual). These probe configurations are referred to as "loggers" in this paper. The loggers were placed in the lowermost $0.1-0.3 \mathrm{~m}$ of the screened section of a well and programmed to measure at one-hour intervals. The minimum temperature signal is at $0^{\circ} \mathrm{C}$. One logger was also installed in a riffle zone of the Brenno river (measurement interval, $5 \mathrm{~min}$; dotted circle in Fig. 1a). While water temperatures vary considerably due to various local conditions (e.g., direct sunlight, pool section), we deemed the location representative for the investigation. The loggers in the wells shown in Fig. 2 operated from November 1999 to April 2001, except that of the river, which was in operation only until 26 September 2000. The loggers in the river and in four wells $(14,16, \mathrm{P} 13$, and S14) were in operation between 28 April and 28 May 1999.

The second site is located in a small flood plain about $5 \mathrm{~km}$ upstream of the first site. It consists of an approximately $100 \mathrm{~m}$ long straight channel with a width of about $5 \mathrm{~m}$ and at an altitude of about $910 \mathrm{~m}$ a.s.l. (Fig. 1b). At this site, the river is losing water to the subsurface. The river slope is about six per cent. The riverbed and the aquifer consist of the same material as at the first site, but the riverbanks are artificially stabilized with large boulders. Downstream of the studied reach, the alluvium thins out to a knick point, where the river becomes gaining. The water temperature of the river was logged continuously about $1 \mathrm{~km}$ downstream of the site (Meier et al., 2001). At the site, three clusters of two monitoring wells were pushed into the riverbed, down 
Table 1. Seasonal trend of temperature data in Brenno river and adjacent monitoring wells. Travel time $\bar{\tau}_{T}$ of temperature fluctuations according to seasonal trend and by cross-correlation of high-frequency components. Logger placement, lowermost $0.1-0.3 \mathrm{~m}$ of screened section of well

\begin{tabular}{cccccc}
\hline Well & Mean T $\left[{ }^{\circ} \mathrm{C}\right]$ & Amplitude $[\mathrm{K}]$ & $\bar{\tau}_{T}$ seasonal [days] & $\bar{\tau}_{T}$ high frequ. [days] & $\max \left(\rho^{2}\right)[-]$ \\
\hline Brenno & 9.75 & 3.94 & N.A. & & \\
8 & 9.79 & 0.95 & 86.6 & $(>30)^{1}$ & 0.02 \\
13 & 10.02 & 2.75 & 22.0 & 5.4 & 0.63 \\
14 & 10.98 & 4.67 & 19.8 & 8.0 & 0.55 \\
16 & 9.31 & 3.67 & 15.5 & 1.8 & 0.81 \\
18 & 10.20 & 3.49 & 42.6 & $(11.5)^{1}$ & 0.24 \\
23 & 11.23 & 2.14 & 33.6 & 2.5 & 0.67 \\
24 & 9.85 & 2.29 & 35.6 & $(4.9)^{3}$ & 0.46 \\
25 & 10.28 & 3.93 & 6.5 & $(12.9)^{1}$ & 0.67 \\
27 & 10.50 & 1.00 & 18.0 & & 0.14 \\
\hline too low correlation & & & \\
2 & \\
influenced by tributary creek &
\end{tabular}

to depths of 1.4 and $1.9 \mathrm{~m}$, respectively (well 1 , only $1.0 \mathrm{~m}$, see Fig. 1b). The monitoring wells consist of stainless steel tubes (diameter $0.05 \mathrm{~m}$ ), with slots of a diameter of $1 \mathrm{~mm}$, at the lowermost $0.2 \mathrm{~m}$ of the tubes. Some smearing of the temperature signal is inevitable at the chosen length of the slotted section. They were instrumented with the same type of data loggers as the ones used at the first site in order to monitor diurnal temperature variations in the hyporheic groundwater. The loggers in the river and in wells 5 and 6 operated in the period from June 1999 to October 2000. The loggers in the other wells failed within this period and thus have shorter measurement periods.

\section{Results and discussion}

\subsection{Seasonal trends at the first site}

Figure 2 shows a period between May 1999 and April 2001, within which the temperature time series are given for the Brenno river and selected monitoring wells. The river temperature fluctuated daily, and in the wells scatter of variable extent can be observed. Seasonal trends were determined by least-square fitting of a constant mean as well as sineand cosine-functions with a period of 365 days. These fitted curves are included in the figure. Table 1 lists the fitted parameters. Excluding systematic errors in the measurements, the mean temperatures and the amplitudes of the temperature fluctuations could be determined to an accuracy of $0.01 \mathrm{~K}$.

The river temperature had a mean value of $9.8^{\circ} \mathrm{C}$ and a seasonal amplitude of about $3.9 \mathrm{~K}$. With the exception of well 16, the mean temperatures in all groundwater wells were higher than that in the river. This is in disagreement with the conceptual model of strictly one-dimensional convectiveconductive heat transfer between the river and the various observation wells. The observed shift of the mean temperature in the monitoring wells indicates that temperature is also affected by local recharge and by vertical conductive heat transfer from the soil surface. At the monitoring site, the average surface temperature is higher than the average river temperature, resulting also in a higher mean temperature. Additional tracer information would be required to quantify the amount of mixing between river water and local recharge in the wells. The amplitude of seasonal temperature fluctuations was maximal in the river and in well 25 , which is influenced by seepage water from the valley slopes, and minimal in wells 8 and 27 (about $1 \mathrm{~K}$ ).

The travel time of the seasonal temperature fluctuations, $\bar{\tau}_{T}$, between the Brenno river and the wells was computed from the phase shifts of the sinusoidal fits. Requiring that the sum of squared residuals of the fitted temperature time series meets its expected value, we computed the epistemic error of the measurements. From these, we could determine the accuracy of the estimated temperature travel times by linearized error propagation. The corresponding standard deviations of estimation were about 0.4 days. The travel times of the temperature fluctuations were minimal in well 25 and maximal in well 8 , which compares with the temperature amplitude data. The fitted seasonal parameters listed in Table 1 result from the various contributions of hyporheic, alluvial and hillslope groundwater. Thus the travel time of the seasonal temperature fluctuations cannot be used for assessing groundwater residence times. 


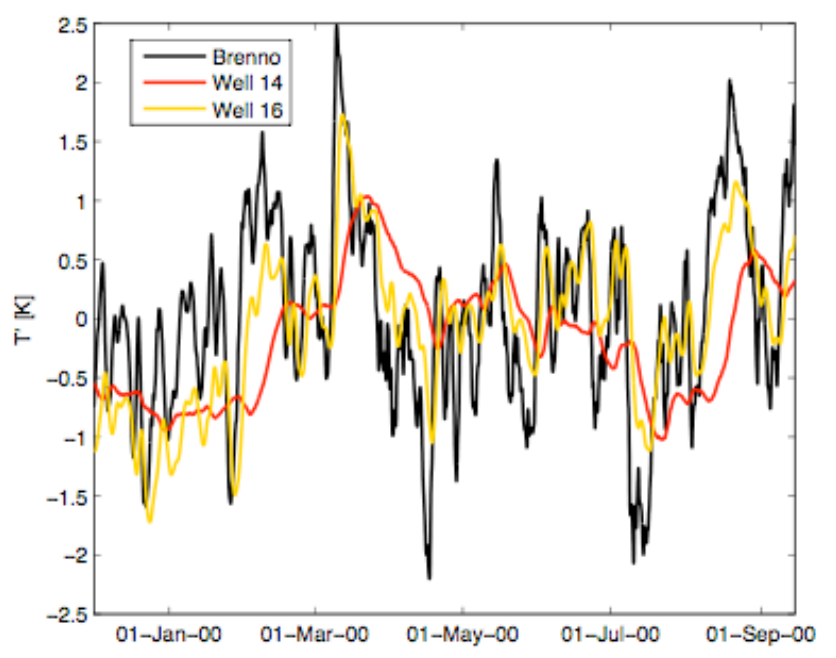

Fig. 3. Temperature fluctuations in Brenno river and two selected wells (14 and 16) after removal of seasonal trend. Data smoothed by taking moving averages over two days.

\subsection{High-frequency temperature fluctuations at the first site}

In a subsequent step, we analyzed the residuals of the temperature time series after spectral filtering, i.e., removing the seasonal trend. Figure 3 shows the resulting temperature fluctuations in the river and two selected wells (14 and 16). These wells were chosen because they showed the most pronounced structure in the residuals (see Fig. 2). The structure in the river signal may reflect weather-related fluctuations at the soil and river surface (radiation, sensible and latent heat fluxes) in the river catchment, or they are caused by fluctuations in river discharge (i.e., flash-flood events, water releases during hydropower operations). Without detailed investigations about all relevant properties of the catchment, the exact cause of the river signal cannot be identified. In the present analysis, however, the latter is not necessary because we are only interested in the transfer from the river to the observation wells. Figure 3 clearly shows that the signals measured in the river are propagated to well 14 and 16. Wells 23 and 25 also showed a distinct pattern in the temperature time series. The latter wells, however, were strongly affected by infiltration from a tributary creek and by seepage water from the hill slopes, respectively, while wells 14 and 16 appeared to be dominated by infiltration from the Brenno river. The data shown in Fig. 3 are smoothed by taking the moving average over two days. Well 16 mostly reacted faster to highfrequency temperature fluctuations than well 14. The signal in well 14 is more dampened than the others. We analyzed the residuals of the wells of Table 1 by cross-correlation:

$\rho_{T_{1} T_{2}}^{2}(\tau)=\frac{\overline{\left(T_{1}(t+\tau)-\bar{T}_{1}\right)\left(T_{2}(t)-\bar{T}_{2}\right)_{1}}}{\sigma_{T_{1}} \sigma_{T_{2}}}$,

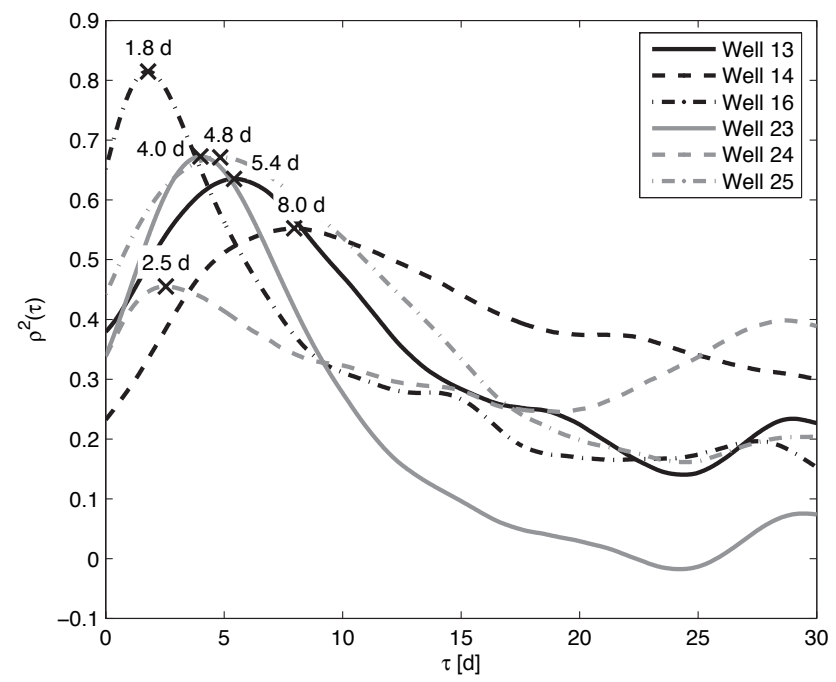

Fig. 4. Cross correlation of high-frequency temperature signals in selected wells with that of Brenno river.

in which $\rho_{T_{1} T_{2}}^{2}(\tau)$ is the cross-correlation function between the time series $T_{1}$ and $T_{2}$, overbars denote time averages and $\sigma_{T_{i}}$ is the temporal standard deviation of time series $T_{i}$. The time of the first and highest peak in $\rho_{T_{1} T_{2}}^{2}(\tau)$ is an indicator for the travel time of the temperature signal. Figure 4 shows the computed correlation functions between the temperatures in some wells and the Brenno river. Table 1 includes the time shift of maximum correlation, denoted as high-frequency $\bar{\tau}_{T}$, and the value of $\max \rho_{T_{1} T_{2}}^{2}(\tau)$ for these wells. An implicit assumption in the application of cross-correlation techniques is that the response of a well to a signal fluctuation in the river is invariant with respect to translation in time. The latter would imply steady-state flow, which is clearly not given over the time period considered here. Therefore, the time shifts of maximum correlation are indicative for the effective transfer of temperature, averaged over various flow regimes, and weighted by the magnitude of the signal transferred at a given time. For most wells, the high-frequency travel time computed is significantly smaller than the seasonal value assessed in the previous section. For the wells 14,16 , and 18 , we postulate a high portion of hyporheic groundwater that originates from downwelling of the Brenno river. The high correlation between the Brenno river and well 25 , unfortunately, is not caused by a good hydraulic connection between the river and the well. Well 25 tapped shallow hill-slope groundwater, which is influenced by temperature fluctuations that look similar to those observed in the river. Well 23, which also exhibits high correlation, is influenced by a tributary creek (Well 3 in Holocher et al., 2001). We postulate that the latter creek had a similar, but not identical temperature signal as the Brenno river. The difference becomes obvious in the two distinct peaks of low temperature around the change of year 1999/2000, which appear in well 23 but not in the Brenno river (see Fig. 1). 
Table 2. Sulphate concentration $\left(\mathrm{SO}_{4}\right)$ and estimated fraction of infiltration water $\left(f_{\text {inf }}\right)$, based on $\mathrm{SO}_{4}$ data, radon concentrations $(\mathrm{Rn})$ and estimated radon water age $\left(\tau_{\mathrm{Rn}}\right)$, based on $\mathrm{Rn}$ data; water travel time $\left(\bar{\tau}_{w}\right)$, estimated from time shift of maximum correlation of highfrequency temperature fluctuations, assuming a temperature retardation of $R_{T}=3$. For validity of estimates, see text.

\begin{tabular}{cccccccc}
\hline Well & \multicolumn{2}{c}{12 April 2000} & \multicolumn{2}{c}{12 April 2000} & \multicolumn{3}{c}{18 October 2000} \\
& $\mathrm{SO}_{4}$ & $f_{\text {inf }}$ & \multicolumn{1}{c}{$c_{\mathrm{Rn}}$} & $\tau_{\mathrm{Rn}}$ & $c_{\mathrm{Rn}}$ & $\tau_{\mathrm{Rn}}$ & $\bar{\tau}_{w}$ \\
& {$[\mathrm{mmol} / \mathrm{L}]$} & {$[-]$} & {$[\mathrm{Bq} / \mathrm{L}]$} & {$[$ days $]$} & {$[\mathrm{Bq} / \mathrm{L}]$} & {$[$ days $]$} & {$[$ days] } \\
\hline Brenno & 1.8 & 1.0 & $<1$ & 0.0 & $<1$ & 0 & \\
8 & - & - & - & - & 35 & $>15$ & $(>10)^{1}$ \\
13 & 0.3 & 0.0 & 4 & 0.4 & 8 & 1 & 1.8 \\
14 & 1.7 & 0.9 & 9 & 2 & 8 & 1 & 2.7 \\
16 & 1.4 & 0.7 & 12 & 3 & 7 & 1 & 0.6 \\
18 & - & - & - & - & 23 & 9 & $(4)^{1}$ \\
25 & 0.4 & $<0.1$ & 32 & $>15$ & - & - & 3 \\
27 & - & - & - & - & 13 & 3 & $(4.3)^{1}$ \\
\hline
\end{tabular}

1 too low correlation

3 influenced by seepage water from valley slopes

- , not analyzed

\subsection{Comparison of temperature data with tracer informa- tion}

Table 2 shows sulphate and radon tracer concentration data. For the assessment of hypothesized binary mixing in the wells, denoted as fraction of infiltration water $\left(f_{\text {inf }}\right)$, the sulphate concentrations of the Brenno river, $1.8 \mathrm{mmol} / \mathrm{L}$ (highest measured concentration), and of well $13,0.3 \mathrm{mmol} / \mathrm{L}$ (lowest concentration of alluvial ground water), were used as end members. Radon groundwater age could be estimated from ${ }^{222} \mathrm{Rn}$ concentrations between $c_{0}<1 \quad B q / \mathrm{L}$ (Brenno river; lowest concentration) and $c_{\infty}=35 \mathrm{~Bq} / \mathrm{L}$ (well 8; highest concentration of alluvial ground water, hypothesized to be at steady state). Using Rn concentrations near the detection limit as end member for surface waters is a straightforward assumption because of rapid outgassing in the river. Using the highest measured $\mathrm{Rn}$ concentration in alluvial ground water as $c_{\infty}$ is justified by the high number of $39 \mathrm{Rn}$ measurements (not shown here; see Hoehn, 2001) that exhibit normal rather than log-normal distribution. Wells 14 and 16 have high sulphate and low radon concentrations, which conforms with the temperature data: high fraction of hyporheic groundwater of Brenno river-water origin and small residence time. Well 25 has high radon $(32 \mathrm{~Bq} / \mathrm{L})$ and low sulphate concentrations, which corroborates the assumption that this well taps older water not of riverbed and bank infiltration origin. Well 13 has low radon and sulphate concentrations, which is interpreted as young water, but not of Brenno river water origin.

In Table 2, the radon water ages are compared with the groundwater residence time, calculated from the highfrequency travel time of temperature fluctuations, assuming a retardation factor of the water temperature $R_{T}=3$. A good correlation was found, although some values of $\tau_{\mathrm{Rn}}$ are higher and some are lower than those of $\bar{\tau}_{T}$. Well 8 has a high radon concentration and small temperature variations, indicating older alluvial groundwater not of Brenno river water origin. Well 27 revealed relatively low radon concentrations. Because of the consistently low natural temperature variations, this young groundwater is probably not of bankinfiltration origin. Holocher et al. (2001) found that the water ages increase in winter with decreasing groundwater levels. The contribution of younger near-surface waters decreases in winter because precipitation is stored temporarily in the snow cover.

From the linear flow distances and the water travel times of Table 1, values for the groundwater flow velocity were assessed for the wells 13, 14, 16, and 18, ranging from 3$100 \mathrm{~m} /$ day. Assuming $n_{e}=0.2$, an aquifer thickness of $10 \mathrm{~m}$ and groundwater hydraulic gradients in the order of the topographic gradient of the flood plain (i.e. about 0.03 ), values for transmissivity range from $2-80 \times 10^{-3} \mathrm{~m}^{2} / \mathrm{s}$, which is consistent with the transmissivity of $5 \pm 3 \times 10^{-3} \mathrm{~m}^{2} / \mathrm{s}$, found by the pumping tests of CREA (2005) ${ }^{1}$.

Figure 5 shows diurnal temperature fluctuations in well S14 from 15 to 28 May 1999. This figure exemplifies how the intensity of infiltration decreases with time. A minor flood in Brenno river on 20 May 1999 with a discharge rate of about $18 \mathrm{~m}^{3} / \mathrm{s}$ is indicated in this figure by the humps in the time series of the water levels. After this flood, the diurnal temperature fluctuations in well S14 were fairly high. Over the next 8 days, the amplitude of these fluctuations gradually decreased, indicating weaker downwelling. The decrease in daily temperature variation in hyporheic groundwater is explained with an increase of clogging in the riverbed and a decreasing river-groundwater exchange. Clogging seems to be a process that starts within days after a flood event to be more and more effective. Unfortunately, well S14 broke during a flood in September 1999, and the observations could not be repeated. 


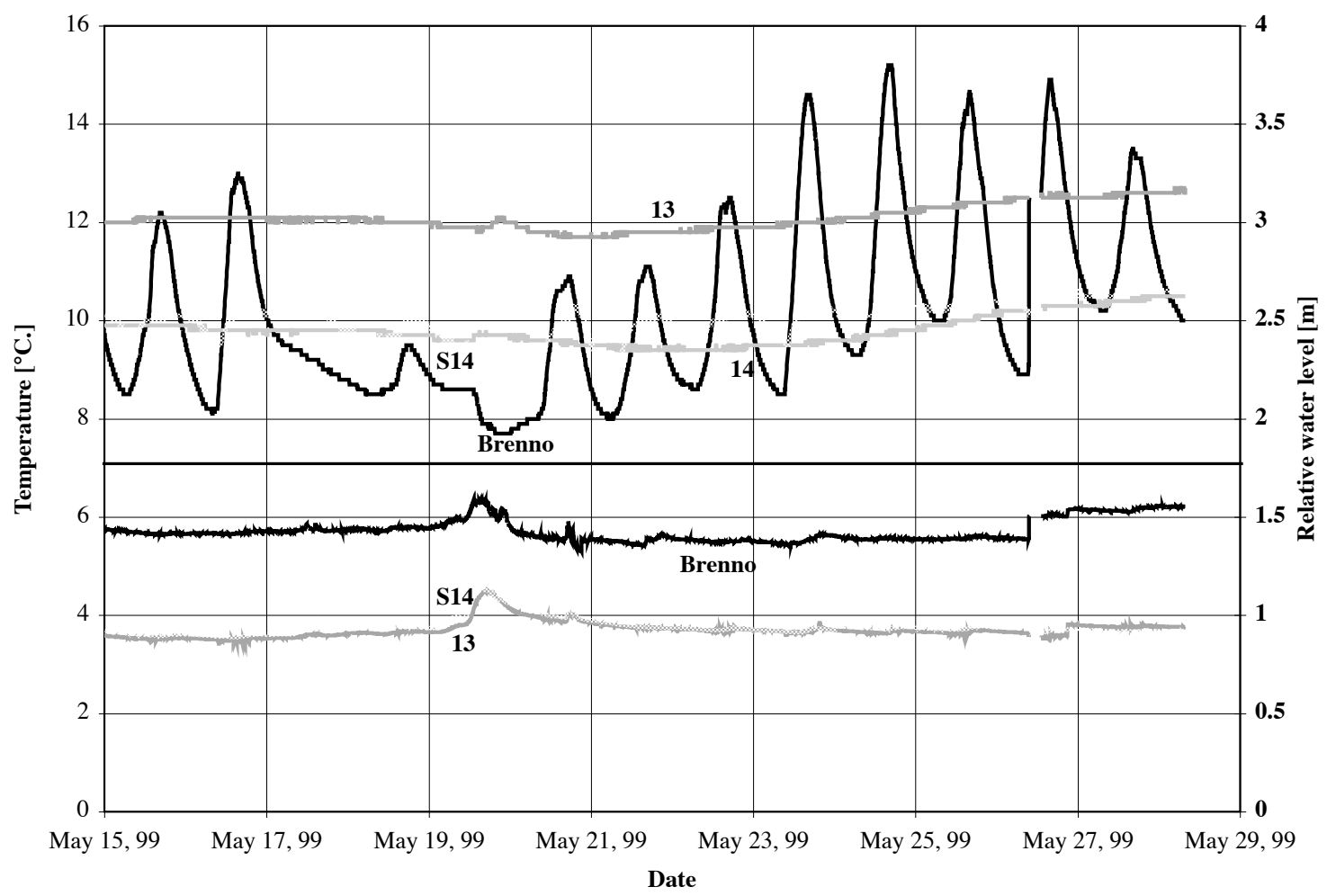

Fig. 5. Relative water level (curves below straight line) and water temperature (curves above straight line) time series of Brenno river and selected monitoring wells (13, 14, S14), 15-28 May 1999.

\subsection{Second site}

Diurnal water temperature variations were observed between June 1999 and October 2000, in the 6 monitoring wells located in the hyporheic zone of the riverbed at the second site. Figure 6 shows the temperatures in the wells 2-6 in the period between June and November 1999. The temperatures of all wells go more or less in parallel. Since these wells are very shallow, diurnal signals could be studied. Figure 7a shows a one-week section of temperatures observed in the wells in summer 1999. We extracted the diurnal signal from the temperature data in wells $2-6$ by fitting sinusoidal functions with wave lengths of $2 \mathrm{~h}, 4 \mathrm{~h}, 6 \mathrm{~h}, 12 \mathrm{~h}$, and $24 \mathrm{~h}$ to the data collected between 11 May and 18 November. These frequencies cover the range from the Nyquist frequency, corresponding to a wavelength of twice the resolution scale (e.g., Press et al., 1992, Sect. 12.1) to the diurnal signal. Figure 7b shows the extracted diurnal signal. The times of daily peak temperature vary by about $4 \mathrm{~h}$. If travel times are on the scale of a few days, the daily signal may already be too weak. Also, a mismatch by multiples of $24 \mathrm{~h}$ is possible. The temperature time series of the logger in the river could not be used for the study of diurnal signals because the logger was placed too far away from the pushed wells for comparison. Well 6 was taken instead for comparison with the other wells because here the daily temperature maximum occurred the
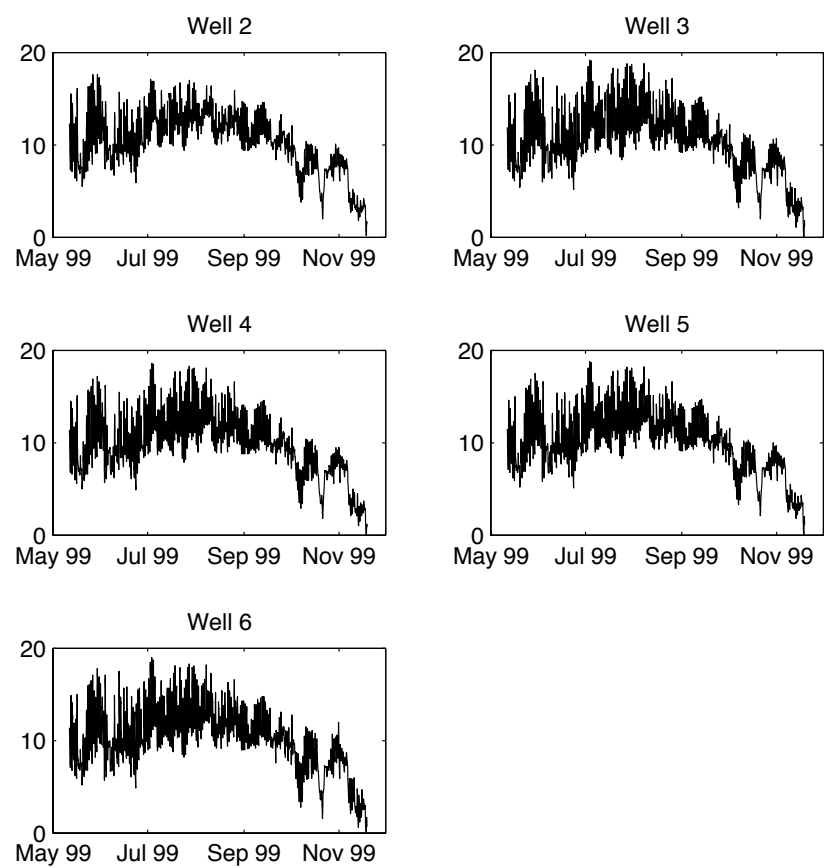

Fig. 6. Time series of water temperature $\left[{ }^{\circ} \mathrm{C}\right]$ in monitoring wells 2-6 of second site, 11 May 1999 to 18 November 1999. 

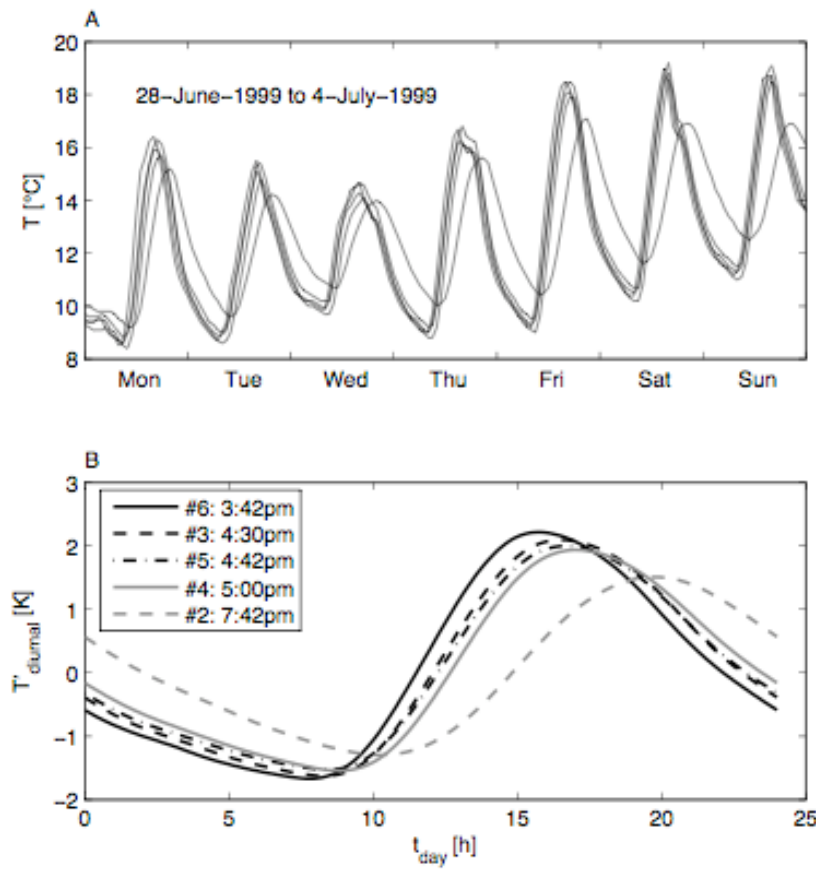

Fig. 7. Water temperature time series in monitoring wells 2-6, second site. (a) One-week section in summer 1999. (b) Diurnal temperature fluctuations, averaged over time period from 11 May to 18 November 1999. Inset includes day time of peak temperature.

earliest. Assuming a temperature retardation factor of $R_{T}=3$, the delay of temperature peaks in well 2 of about $4 \mathrm{~h}$ yields a residence time of the water to reach the depth of $1.9 \mathrm{~m}$ of about $\bar{\tau}_{w}=1.3 \mathrm{~h}$. The average linear groundwater flow velocity calculates to $1.5 \mathrm{~m} / \mathrm{h}$. Assuming a hydraulic gradient on the order of the slope of the river (about 6 per cent), and $n_{e}=0.2$, a hydraulic conductivity of about $1 \times 10^{-3} \mathrm{~m} / \mathrm{s}$ would result for the river bed, which is high and results probably from the coarse-grained material.

Pushing monitoring wells into the riverbed may have led to a short-cut of flow from the river to the hyporheos and the well screens. Thus the course of the water temperatures in the wells was compared with sediment temperatures, to determine whether the water temperatures in wells represent temperatures in the adjacent sediment. On 30 June 1999, Meier (2001) inserted temperature loggers at three different depths into the Brenno riverbed sediment $(0.21,0.28$, and $0.54 \mathrm{~m})$, about $1 \mathrm{~km}$ downstream of the second site. In the period between 3 and 31 July 1999, the diurnal temperature variations were $0.3-2.8 \mathrm{~K}$ at a depth of $0.21 \mathrm{~m}, 0-1.2 \mathrm{~K}$ (depth: $0.28 \mathrm{~m}$ ), and not detectable at a depth of $0.54 \mathrm{~m}$. The temperature variations do not seem to be significantly different from the well data. In a similar study by Constantz et al. (2002), the agreement was excellent at a depth of $0.3 \mathrm{~m}$, and measurements in the monitoring wells provided an accurate estimate of the temperature variations, as long as stream flow was present.

\section{Conclusions}

We have shown how groundwater temperature can be used as a tracer for fresh infiltration of river water. Seasonal temperature fluctuations do not carry a unique signal because all shallow groundwater components, regardless of their origin, show fluctuations on this time scale. It is impossible to infer the fractions and phase shifts of the various components from the mixed temperature signal observed in a well. At our first site, the apparent travel times of temperature propagation were significantly higher for the seasonal signal than for fluctuations on the scale of one to a few days. We believe this to be typical for situations in which groundwater of different origin and age mixes. In groundwater resources protection, the fastest groundwater component is the most relevant one. The travel time, determined from shifts in seasonal temperature fluctuations, would exceed the travel time of the youngest groundwater component, pretending better than real protection. Thus, the seasonal signal should not be used in order to determine the groundwater age.

Residence times of the contribution of freshly infiltrated water from a river to a drinking-water well can be calculated from continuous time-series of temperature or specific electrical conductivity. They help to better assess the contamination risk and implement protective measures.

Diurnal temperature fluctuations are attenuated over short travel distances and can be used as a tracer for freshly infiltrated water at travel distances of a few meters under strongly infiltrating conditions. This was demonstrated at our second site, where travel times did not exceed a few hours. Fluctuations on the time scale of a few days penetrate deeper into the aquifer than the diurnal signal. Often, these fluctuations are still unique for freshly infiltrated river water. They are caused by weather changes, which also affect the temperature of the recharged alluvial water and the water in tributaries, or they are the result of changes in river discharge. Fluctuations on the time scale of a few days are less regular than diurnal changes, making the signal more unique, which helps preventing mismatch of peaks.

Our studies also indicate that the analysis of water temperatures should be combined with other natural tracers, helping to identify the origin of groundwater samples and its age. For the origin, geochemical characteristics, such as the sulphate concentration used in our study, may be used, while the age of young groundwater components can be inferred from ${ }^{222} \mathrm{Rn}$ concentrations. Had the temperature study at the 2 nd site been embedded in other investigations (tracers, geophysics, hydraulic testing), the results on residence times of hyporheic ground water to reach the pushed wells would have been more reliable.

Acknowledgements. Substantial support from Eawag's multidisciplinary research Project "Green Hydropower" is acknowledged. We thank H. Burkhalter and the EAWAG Technical Services for the installation of the monitoring wells, and U. Lüchinger (CREA) for continuous logger management. The "Consorzio Risanamento 
Ecosistemi Alluviali" (CREA) and the authorities of the Canton Ticino (Sezione Protezione Aria ed Acqua, SPAA) helped with fruitful discussions, during common project meetings. Discussions with T. Gonser, A. Wüest and R. Kipfer were helpful.

Edited by: A. D. Reeves

\section{References}

Anderson, M. P.: Heat as a ground water tracer, Ground Water, 43(6), 951-968, 2005.

Bonnard, E., Karagounis, I., Kempf, T., and Walter, U.: Abkühlung des Grundwassers durch Wärmenutzung, Gas-Wasser-Abwasser, 71(1), 5-36, 1991.

Bertin, C. and Bourg, A. C. M.: Radon-222 and chloride as natural tracers of the infiltration of river water into an alluvial aquifer, Environ. Sci. Technol., 28(5), 794-798, 1994.

Bourg, A. C. M. and Bertin, C.: Seasonal and spatial trends in manganese solubility in an alluvial aquifer, Environ. Sci. Technol., 28(5), 868-876, 1994.

Brunke, M., Hoehn, E., and Gonser, T.: Patchiness of rivergroundwater interactions within two floodplain landscapes and diversity of aquatic invertebrate communities, Ecosystems, 6(8), 707-722, 2003.

Brunke, M.: Floodplain of a regulated southern alpine river (Brenno, Switzerland): ecological assessment and conservation options, Aquatic Conserv.: Mar. Freshwater Ecosyst., 12, 583599, 2002.

Brunke, M. and Gonser, T.: The ecological significance of exchange processes between rivers and groundwater, Freshwater Biol., 37, 1-33, 1997.

Constantz, J., Stewart, A. E., Niswanger, R., and Sarma, L.: Analysis of temperature profiles for investigating stream losses beneath ephemeral channels, Water Resour. Res., 38(12), 13161328, 2002.

de Marsily, G.: Quantitative Hydrogeology, Academic Press, Orlando, USA, 1986.

Domenico, P. A. and Schwartz, F. W.: Physical and chemical hydrogeology, J. Wiley and Sons, New York, USA, 1990.

Hoehn, E. and von Gunten, H. R.: Radon in groundwater - a tool to assess infiltration from surface waters to aquifers, Water Resour. Res., 25(8), 1795-1803, 1989.

Hoehn, E.: Hydrogeological issues of riverbank filtration - a review, in: Riverbank filtration: understanding contaminant biogeochemistry and pathogen removal, edited by: Ray, C., NATO Sci. Ser., IV, Earth Environ. Sci., 14, 17-42, 2002.

Hoehn, E.: Identification of groundwater habitats using radon as a tracer, Eawag-News 52e, p. 19/20, http://www.eawag.ch/ publications/eawagnews/www_en52/en52e_ihv_web.htm, 2001.

Holocher, J., Matta, V., Aeschbach-Hertig, W., Beyerle, U., Hofer, M., Peeters, F., and Kipfer, R.: Noble gas and major element constraints on the water dynamics in an Alpine floodplain, Ground Water, 39(6), 841-852, 2001.
Huggenberger, P., Hoehn, E., Beschta, R., and Woessner, W. W.: Abiotic aspects of channels and floodplains in riparian ecology, Freshwater Biol., 40, 407-425, 1998.

Jäckli, H. and Ryf, W.: Die Grundwasserverhältnisse im unteren aargauischen Aaretal, Wasser, Energie, Luft, 70(3/4), 53-61, 1978.

Logan, J. D.: Solute transport in porous media with scale-dependent dispersion and periodic boundary conditions, J. Hydrol., 184, 261-276, 1996.

Mazor, E. and Vuataz, F. D.: Hydrology of a spring complex, studied by geochemical time-series data, Acquarossa, Switzerland, Appl. Geochem., 5(5/6), 563-569, 1990.

Meier, W.: Modellierung der Auswirkungen von Wasserkraftanlagen auf physikalisch-chemische Eigenschaften von Bergbächen, Dissertation ETH no. 14526, Swiss Federal Institute of Technology Zurich, Switzerland, 2002.

Pastorelli, S., Marini, L., and Hunziker, J. C.: Water chemistry and isotope composition of the Acquarossa thermal system, Ticino, Switzerland, Geothermics, 28(1), 75-93, 1999.

Press, W. H., Teukolsky, S. A., Vetterling, W. T., and Flannery, B. P.: Numerical Recipes in Fortran 77: The Art of Scientific Computing, 2nd edition, Cambridge University Press, Cambridge, UK, 1992.

Sauty, J. P.: The effect of thermal dispersion on injection of hot water in aquifers, 2nd Well Testing Symp., Berkeley, CA, USA, 1978.

Schälchli, U.: Die Kolmation von Fliessgewässersohlen: Prozesse und Berechnungsgrundlagen, Dissertation ETH no. 10293, Swiss Federal Institute of Technology Zurich, Switzerland, 1993.

Sophocleus, M.: Interactions between groundwater and surface water: the state of the science, Hydrogeol. J., 10, 52-67, 2002.

Stanford, J. A. and Ward, J. V.: An ecosystem perspective of alluvial rivers: connectivity and the hyporheic corridor, J. N. Amer. Benthol. Soc., 12(1), 48-60, 1993.

Stanford, J. A., Ward, J. V., and Ellis, B. K.: Ecology of the alluvial aquifers of the Flathead River, Montana. Groundwater Ecology, edited by: Gibert, J., Danielopol, D. L., and Stanford, J. A., Academic Press, 1994.

Triska, F. J., Duff, J. H., and Avanzino, R. J.: Influence of the exchange flow between the channel and hyporheic zuone on nitrate production in a small mountain stream, Can. J. Fisheries \& Aquatic Sci., 47, 2099-2111, 1990.

Truffer, B., Bratrich, C., Markard, J., Peter, A., Wüest, A., and Wehrli, B.: Green Hydropower: the contribution of aquatic science research to the promotion of sustainable electricity, Aquatic Sci., 65(2), 99-110, 2003.

Von Gunten, H. R., Karametaxas, G., Krähenbühl, U., Kuslys, M., Giovanoli, R., Hoehn, E., and Keil, R.: Seasonal biogeochemical cycles in riverborne groundwater, Geochim. Cosmochim. Acta, 55(12), 3597-3609, 1991. 